\title{
競合リスク理論に基づく破壊位置の確率論とそ光の応用*
}

\author{
松尾陽太郎***北上浩一**** \\ On'the Statistical Theory of Fractured Location Combined \\ with Competing Risk Theory and its some Applications
}

\author{
by Yōtarō MATSUO and Kōichi KITAKAMI
}

\begin{abstract}
Finnie et al. developed the statistical theory of fractured location which can estimate not only fracture stress but also fractured location. Some researchers analysed several problems using this theory and proved its validity. However, these studies are restricted to only one kind of fracture origin. In this work we have suggested a new theory combining the competing risk theory with the statistical theory of fractured location. Using this theory we derived the distributions of fractured location, corrected stress (a stress at the location of the fracture origin), the depth of the fracture origin, and the defect size. The fitnesses between the theory and the experimental data were fairly good.
\end{abstract}

Key Words: Fracture, Statistics, Fractured Location, Competing Risks, Weibull Distribution, $\mathrm{Si}_{3} \mathrm{~N}_{4}$

\section{1. 緒霄}

粠造用セラミックスは，種々の渗れた性質から新し い絜材として注目されている。こうした状沿に対応し て確率統計諭と破壊力学に基づく強度の信賴性解析が 盛んに行われるようになった。

中で Bolotin ${ }^{(1)}$ ，著者の一人 ${ }^{(2) \sim(5)}$, Johnson ${ }^{(6)}$ は多

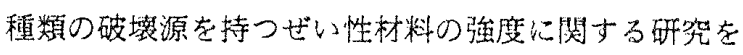
最弱リンク説に基づいて行ってきた（多重モードワイ プル分布を使用）。また，多軸応力状態にも適用できる

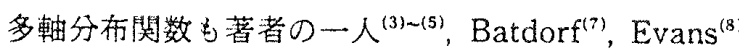
らによって求められている。さらに萻者らは多重モ一 ドワイブル分布のパラメータ推定法として踥合リスク

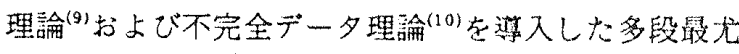
法を提唱し推定精度の向上を計っだ(18)。

一方，Finnie ら (11) 破壊応力のみならず破壤位国 も推定できる理論（位圆の確率論と呼ぶ）を提唱しが ラス板への鋼球の押し込み問題の解析，ガラス侙駼片 の三点曲げ問題の解析を行っている。また，AOKI $ら^{(12)}$ 破堘応力と破壤位置の分布の時間的变化に関

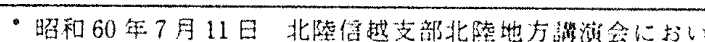

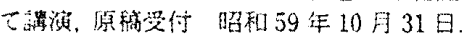

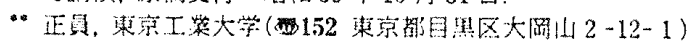

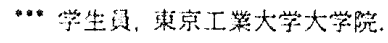

する解析やガラス平板の三点占よず四点曲げ荤礼破壊 の解析を行ってい当。しかし破筫源が複数ある場合の 位䁌の確率論についていまだ呏究がなされていない。

本諭女では，親合りスク理論と位置の確率論とを結 合した理論を新たに提案し，その心用として破壊位置 の分枋，修正応力（破滾源位珇での応力）の分布，破壊

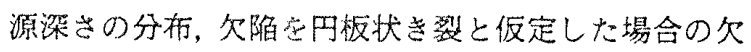
陷寸法の分布を求め，の有効性を明らかにするもの である。

\section{2. 理 論 解 析}

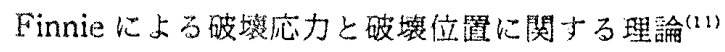
を次のように抬張する。すな⿰力口基準応力" $\sigma_{m} \sigma_{m}$ が $\left(\sigma_{m}\right.$, $\left.\sigma_{m}+d \sigma_{m}\right)$ )間にある物体が領域 $A_{i}$ に打ける位珇 にて破壤する確率は $h_{A_{i}}\left(\sigma_{m}, \xi\right)$ をその結合密度関数と すると次式のように急さ下せる(11).

$$
h_{A_{t}}\left(\sigma_{m}, \xi\right) d \xi d \sigma_{m}=\exp \left(-B_{i}\right) \frac{\partial}{\partial \sigma_{m}}\left(G_{i}\right) d \xi d \sigma_{m}
$$

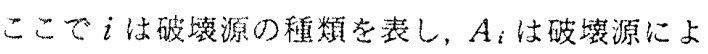

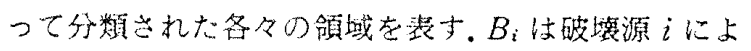

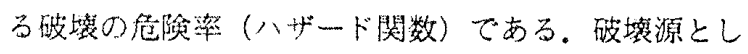

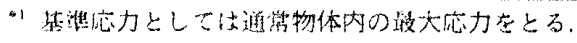


て, 内部き裂 $(i=1)$, 表面き裂 $(i=2)$ ，エッジき裂 $(i=3) 03$ 種類を想定すると，ワイブルの一軸分布関数に対与る $B_{i}, G_{i}$ 棕次式となる。

$$
\left.\begin{array}{l}
B_{1}=\int_{\xi} G_{1} d \xi, G_{1}=\left(\frac{\sigma-\sigma_{u 1}}{\sigma_{01}}\right)^{m_{1}} Y\left(\sigma, \sigma_{u 1}\right)\left(\frac{d V}{d \xi}\right) \\
B_{2}=\int_{3} G_{2} d \xi, G_{2}=\left(\frac{\sigma-\sigma_{u 2}}{\sigma_{02}}\right)^{m_{2}} Y\left(\sigma, \sigma_{u 2}\right)\left(\frac{d A}{d \xi}\right) \\
B_{3}=\int_{3} G_{3} d \xi, G_{3}=\left(\frac{\sigma-\sigma_{u 3}}{\sigma_{03}}\right)^{m_{3}} Y\left(\sigma, \sigma_{u 3}\right)\left(\frac{d L}{d \xi}\right)
\end{array}\right\}
$$

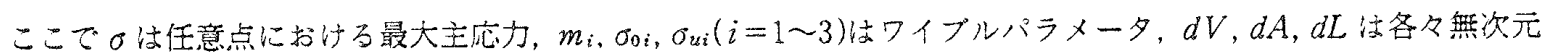

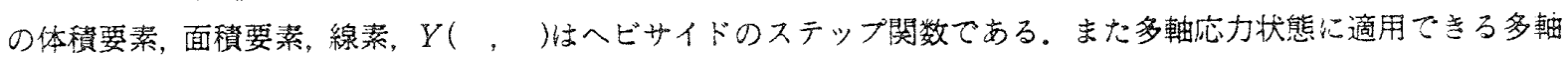
分布関数に対しては，Gi次次式で裚される(3)。

$$
\begin{aligned}
& G_{1}=\frac{2}{\pi} \int_{0}^{\pi / 2} \int_{0}^{\pi / 2}\left(\frac{Z-\sigma_{u 1}}{\sigma_{01}}\right)^{m_{1}} Y\left(Z, \sigma_{u 1}\right) \sin \varphi d \varphi d \theta\left(\frac{d V}{d \xi}\right) \\
& G_{2}=\frac{2}{\pi} \int_{0}^{\pi / 2}\left(\frac{Z^{*}-\sigma_{u 2}}{\sigma_{02}}\right)^{m_{2}} Y\left(Z^{*}, \sigma_{u 2}\right) d \psi\left(\frac{d A}{d \xi}\right) \\
& G_{3}=\left(\frac{Z^{+}-\sigma_{u 3}}{\sigma_{03}}\right)^{m_{3}} Y\left(Z^{+}, \sigma_{l b 3}\right)\left(\frac{d L}{d \xi}\right)
\end{aligned}
$$

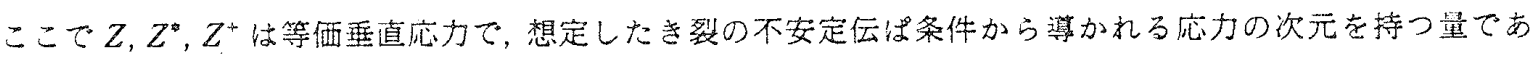
る(3)。さてここで一般には式(1)で表される個々の結合密度関数 $h_{A_{i}}\left(\sigma_{m}, \xi\right)$ を用いて破壊位置と破壤応力に関する

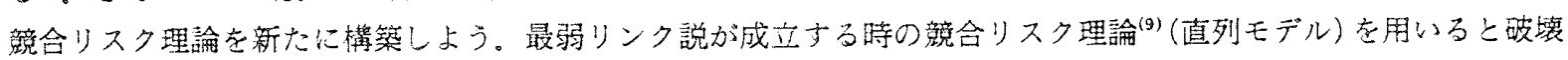
原因が $n$ 種類ある時の競合リスクに対する密度関数はただちに次式のように定式化できる。

$$
h_{i}\left(\sigma_{m}, \xi\right)=\prod_{i=1}^{n} R_{i}\left(\sigma_{m}\right) \times \sum_{j=1}^{n} \lambda_{j}
$$

ここでRiは信頼度, $\lambda_{j}$ 蜘障率で各々次式で与えられる。

$$
\left.\begin{array}{l}
R_{i}\left(\sigma_{m}\right)=1-\int_{0}^{\sigma_{m}} \int_{e t} h_{A_{1}}\left(\sigma_{m}, \xi\right) d \xi d \sigma_{m} \\
\lambda_{j}=h_{A}\left(\sigma_{m}, \xi\right) / R_{j}\left(\sigma_{m}\right), A=\sum_{i=1}^{n} A_{i}
\end{array}\right\}
$$

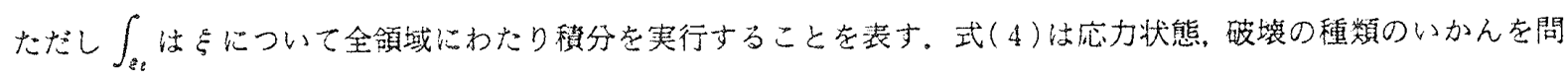

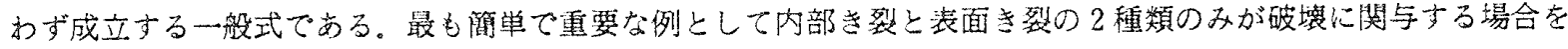
想定する。ただ内部き裂に対する領域を $D$, 表面き裂に対する領域を $\partial D$ で表し、ワイブル分布である式 $(2)$ を 用いる。式(1)，(4)，(5)からただちに次式が成立することがわかる。

$$
\begin{aligned}
& h_{\text {oUวD }}\left(\sigma_{m}, \xi\right)=h_{D}\left(\sigma_{m}, \xi\right) R_{\partial D}\left(\sigma_{m}\right)+h_{\partial D}\left(\sigma_{m}, \xi\right) R_{D}\left(\sigma_{m}\right) \\
& =h_{D}\left(\sigma_{m}, \xi\right)\left\{1-\int_{0}^{\sigma_{m}} \int_{\sigma_{t}} h_{\partial D}\left(\sigma_{m}, \xi\right) d \xi d \sigma_{m}\right\} \\
& +h_{\partial D}\left(\sigma_{m}, \xi\right)\left\{1-\int_{0}^{\sigma_{m}} \int_{\theta_{t}} h_{D}\left(\sigma_{m}, \xi\right) d \xi d \sigma_{m}\right\}
\end{aligned}
$$

次に式（4)，(5)を用いて強度に関する周辺分布 $F\left(\sigma_{m}\right)$ を求めてみる。

すると，

$$
\begin{gathered}
F\left(\sigma_{m}\right)=\int_{0}^{\sigma_{m}} \int_{\xi} h_{A}\left(\sigma_{m}, \xi\right) d \xi d \sigma_{m}=\int_{0}^{\sigma_{m}} \int_{\varepsilon_{j}} \sum_{j=1}^{n}\left\{h_{A}\left(\sigma_{m}, \xi\right) \prod_{\substack{i=1 \\
i \neq j}}^{n} R_{i}\left(\sigma_{m}\right)\right\} d \xi d \sigma_{m} \\
=\int_{0}^{\sigma_{m}} \sum_{j=1}^{n}\left(\frac{d}{d \sigma_{m}} B_{j}\right) \exp \left(-\sum_{i=1}^{n} B_{i}\right) d \sigma_{m}=1-\exp \left(-\sum_{i=1}^{n} B_{i}\right) \ldots \ldots \ldots \ldots \ldots \ldots \ldots \ldots \ldots \ldots \ldots \ldots \ldots
\end{gathered}
$$

上式洨いわゆる多雷モードワイブル分布と正確に一致している。

\section{3.三点曲比試験の解析}

前章で求めた一般式をセラミックス等ぜい性材料の三点曲げ問題に適用し，その密度関数と分布関数を求める。

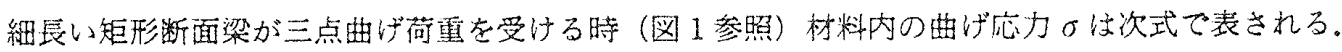




$$
\sigma=\frac{\sigma_{\max }}{h L} x(h-y), \sigma_{\max }=\frac{3 W L}{4 b h^{2}} .
$$

ここで座標 $x, y$ の原点は三点曲げの一方の支点とした。 $\sigma_{u i}=0(i=1 \sim 3)$ とし，はり側面からの破堙を無視でるも のとすると，式 (2)，(8)ょり破壊の危険率 $B_{i}$ は次式となる。

$$
\left.\begin{array}{l}
B_{1}=V_{e 0}\left(\frac{\sigma_{\max }}{\sigma_{n 1}}\right)^{m_{\imath}}, V_{e 0}=\frac{2 b L h}{\left(m_{1}+1\right)^{2}}, B_{2}=A_{e 0}\left(\frac{\sigma_{\max }}{\sigma_{02}}\right)^{m_{2}} \\
A_{e 0}=\frac{2 b L}{m_{2}+1}, B_{3}=L_{e 0}\left(\frac{\sigma_{\max }}{\sigma_{03}}\right)^{m_{3}}, L_{e 0}=\frac{4 L}{m_{3}+1}
\end{array}\right\}
$$

ここで $V_{e 0}, A_{e 0}, L_{e 0}$ は各々無次元の有效体積, 有効䤄積, 有効舆さである。

一軸分布関数を用い, 内部, 表面の 2 種類のき裂のみを考虑した場合には, 式(6)は次の上うになる。

$$
\left.\begin{array}{l}
h_{D \text { vaD }}\left(\sigma_{m}, \xi\right)=h_{D}\left(\sigma_{m}, \xi\right) \exp \left\{-A_{e 0}\left(\frac{\sigma_{m}}{\sigma_{02}}\right)^{m_{2}}\right\}+h_{\partial D}\left(\sigma_{m,}, \xi\right) \exp \left\{-V_{e 0}\left(\frac{\sigma_{m}}{\sigma_{01}}\right)^{m_{1}}\right\} \\
h_{D}\left(\sigma_{m}, \xi\right)=2 b m_{1} \sigma_{m}^{m_{1}-1}\left\{\frac{x(h-y)}{\sigma_{01} L h}\right\}^{m_{1}} \exp \left\{-V_{e 0}\left(\frac{\sigma_{m}}{\sigma_{01}}\right)^{m_{1}}\right\} \\
h_{\partial D}\left(\sigma_{m}, \xi\right)=2 b m_{2} \sigma_{m}^{m_{2}-1}\left(\frac{x}{\sigma_{02} L}\right)^{m_{2}} \exp \left\{-A_{e 0}\left(\frac{\sigma_{m}}{\sigma_{02}}\right)^{m_{2}}\right\}, \sigma_{m}=\sigma_{\max }
\end{array}\right\}
$$

よって結合分布関数は

$$
\begin{aligned}
& H_{D U \partial D}\left(\sigma_{m}, \xi\right)=\int_{0}^{\sigma_{m}} \int_{0}^{a} h_{D U \partial D}\left(\sigma_{m}, \xi\right) d \xi d \sigma_{m} \\
& \quad=\left(\frac{x}{L}\right)^{m_{1}+1}\left\{1-\left(\frac{h-y}{h}\right)^{m_{1}+1}\right\} \int_{0}^{\sigma_{m}} \frac{d B_{1}}{d \sigma_{m}} \exp \left(-B_{1}-B_{2}\right) d \sigma_{m} \\
& \quad+\left(\frac{x}{L}\right)^{m_{2}+1} \int_{0}^{\sigma_{m}} \frac{d B_{2}}{d \sigma_{m}} \exp \left(-B_{1}-B_{2}\right) d \sigma_{m} \ldots \ldots \ldots \ldots \ldots \ldots \ldots . . . \ldots \ldots
\end{aligned}
$$

となる。

\section{4. 窒化珪浆の曲げ試験データの解析と考察}

解析に用いたデータ法伊藤ら(14)によって行われた䇪化球素の三点地げ試駺データであって総数 415 個である。こ

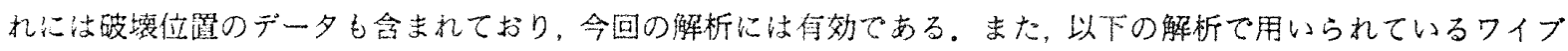
ルパラメー夕 $m_{i}, \sigma_{01}(i=1,2)$ 值を表 1 に示す。これは先に提唱した多段最尤法(15)により求姉た值である(18)。

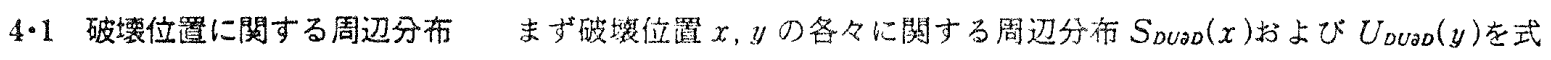
(10)の結合密度関数から求好と, それぞれ次のようになる。

$$
\begin{aligned}
& S_{D U A D}(x)=\int_{0}^{x} \int_{0}^{h} \int_{0}^{\infty} h_{D U \partial D}\left(\sigma_{m}, x, y\right) d \sigma_{m} d y d x \\
& =\left(\frac{x}{L}\right)^{m_{1}+1} \int_{0}^{\infty} \frac{d B_{1}}{d \sigma_{m}} \exp \left(-B_{1}-B_{2}\right) d \sigma_{m}+\left(\frac{x}{L}\right)^{m_{2}+1} \int_{0}^{\infty} \frac{d B_{2}}{d \sigma_{m}} \exp \left(-B_{1}-B_{z}\right) d \sigma_{m} \\
& U_{D U \partial D}(y) \int_{0}^{y} \int_{0}^{L} \int_{0}^{\infty} h_{D U a D}\left(\sigma_{m}, x, y\right) d \sigma_{m} d x d y \\
& \quad=\left\{1-\left(\frac{h-y}{h}\right)^{m_{1}+1}\right\} \int_{0}^{\infty} \frac{d B_{1}}{d \sigma_{m}} \exp \left(-B_{1}-B_{2}\right) d \sigma_{m}+\int_{0}^{\infty} \frac{d B_{2}}{d \sigma_{m}} \exp \left(-B_{1}-B_{2}\right) d \sigma_{m}
\end{aligned}
$$

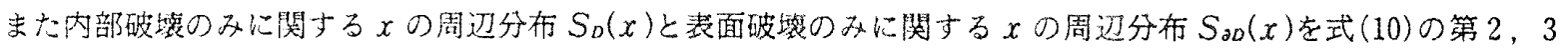
式から求次のようになる。

$$
\begin{aligned}
& S_{D}(x)=\int_{0}^{x} \int_{0}^{h} \int_{0}^{\infty} h_{D}\left(\sigma_{m}, x, y\right) d \sigma_{m} d y d x=\left(\frac{x}{L}\right)^{m_{1}+1}, \\
& S_{\partial D}(x)=\int_{0}^{x} \int_{0}^{\infty} h_{\partial D}\left(\sigma_{m}, x\right) d \sigma_{m} d x=\left(\frac{x}{L}\right)^{m_{2}+1} \ldots \ldots \ldots . . .
\end{aligned}
$$

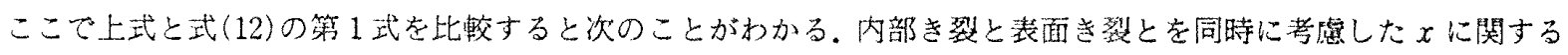

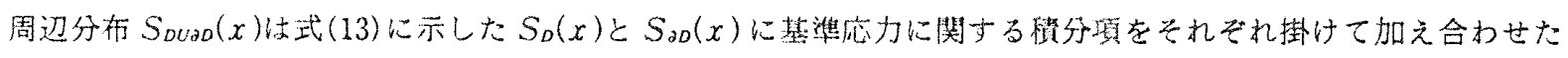
形を取っている。さらにこの积分項は次の上うな绑味を持つ。

$$
\int_{0}^{\infty} \frac{d B_{1}}{d \sigma_{m}} \exp \left(-B_{1}-B_{2}\right) d \sigma_{m}
$$


は，基集応力 $\sigma_{m}$ のみから計算される内部破壦の割 合,

$$
\int_{0}^{\infty} \frac{d B_{2}}{d \sigma_{m}} \exp \left(-B_{1}-B_{2}\right) d \sigma_{m}
$$

流, 基準応力 $\sigma_{m}$ のみから訫算される表面破壊の割合。 つまり式(12)の第1式注，内部破壤と表面破薯心関す る混合分布 (mixture)になっていることがわかる。衰 1 のパラメー夕を用いて $h_{\text {DUวD }}(x), h_{\text {DUaD }}(y), h_{D}(x)$, $h_{\partial D}(x)$ と $h_{D}(y)$ を数値計算した結果を図 $2(\mathrm{a}),(\mathrm{b})$

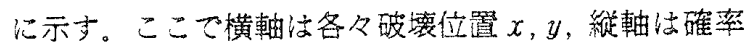

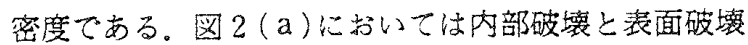
の相互作用が办られ，S S とを哇付けている。

内部破壊の化関子るyの周辺分布 $U_{D}(y)$ 式 (10)の第 2 式から求めると次式となる。

$$
\begin{aligned}
& U_{D}(y)=\int_{0}^{y} \int_{0}^{L} \int_{0}^{\infty} h_{D}\left(\sigma_{m}, x, y\right) d \sigma_{m} d x d y \\
& =1-\left(\frac{h-y}{h}\right)^{m_{1}+1} \ldots \ldots \ldots \ldots \ldots \ldots \ldots \ldots \ldots \ldots \ldots \ldots \ldots \ldots \ldots
\end{aligned}
$$

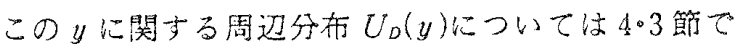
改めて述べる。

式(13)より求めた理論曲線と平均ランク法によりプ ロットした実蛤值を図 3(a)，(b)に示す。理論曲線 は実験值上非常によく一致している。このことから， 破埭応力が未知ても陚験片長手方向( $x$ 方向)について の破壊位置がわかっていれば，ワイブル分布の形状母 数仙推定可能であることがわかる。

4.2 修正応力 ワイプル確率紙を用いて実験デ 一タからワイプル係数老求好る際に，修正忘力（破壊 源位置での応力）を計算してこれをプロットし，それ らのデー夕点に最良フイットさせるように引いた直線 を使用すべきであるとの兒解がある。これに刘して 我々は今回の“破堎㐫力と破壤位置に関する競合リス
ク理論”を用いて上述の見解が愦りであることを示す。 主ず初如式(10)に示された基準応力 $\sigma_{m}$ (最大曲沙沁 力）破燷位置 $\xi$ に関する結合密度関数修正応力 $\sigma_{c}$ ときに関寸る結合密度関数に変数変換する。変数変势 式と積分の変換公式に関するヤコビアンは以下のとょ りである。

$$
\begin{aligned}
& h_{D}\left(\sigma_{m}, \xi\right) \text { に対しては, } \\
& \sigma_{m}=\frac{L h}{x(h-y)} \sigma_{c} \\
& |J|=\left|\frac{\partial \sigma_{m}}{\partial \sigma_{c}}\right|=\frac{L h}{x(h-y)} \\
& h_{\partial D}\left(\sigma_{m}, \xi\right) \text { K刘しては, } \\
& \sigma_{m}=\frac{L}{x} \sigma_{c},|J|=\left|\frac{\partial \sigma_{m}}{\partial \sigma_{c}}\right|=\frac{L}{x} .
\end{aligned}
$$

これらを使って，式(10)の第 $2 ， 3$ 式について変数変 換卞ると次式となる。

$$
\begin{aligned}
& h_{D}\left(\sigma_{c}, \xi\right)=2 b m_{1} \sigma_{c}^{m_{1}-1}\left(\frac{1}{\sigma_{01}}\right)^{m_{1}} \\
& \times \exp \left[-V_{o 0}\left\{\frac{\sigma_{c} L h}{\sigma_{01} x(h-y)}\right\}^{m_{1}}\right] \\
& h_{\partial D}\left(\sigma_{c}, \xi\right)=2 b m_{2} \sigma_{c}^{m_{2}-1}\left(\frac{1}{\sigma_{02}}\right)^{m_{2}} \\
& \times \exp \left[-A_{e 0}\left(\frac{\sigma_{c} L}{\sigma_{02} x}\right)^{m_{2}}\right]
\end{aligned}
$$

式(16)から修正芯力 $\sigma_{c}$ に関する周辺分布を求めると， 内部破壊〔図 4(a)〕の場合も表面破壊〔図 4(b) ) の場合も，なだらかではあるが上にあの曲線となり， $\sigma_{c}$ が 2 母数ワイプル分布に従わ亲いことがわかる゙。 従って $\sigma_{c}$ がワイブル確率紙上で直線になるとしてワ イブル係数を求めることは愦りであることがわかる。 さらに，式(10)の第 1 式に示された $h_{\text {DUaD }}\left(\sigma_{m}, \xi\right) に つ$ いても式(15)の変数変捂を行うと次のようになる。

$$
\begin{aligned}
& h_{D \ell \partial D}\left(\sigma_{c}, \xi\right)=2 b\left(\frac{m_{1}}{\sigma_{01}}\right)\left(\frac{\sigma_{c}}{\sigma_{01}}\right)^{m_{1}-1} \exp \left[-V_{e 0}\left\{\frac{\sigma_{c} L h}{\sigma_{01} x(h-y)}\right\}^{m_{1}}-A_{e 0}\left\{\frac{\sigma_{c} L h}{\sigma_{02} x(h-y)}\right\}^{m_{2}}\right] \\
& +2 b\left(\frac{m_{2}}{\sigma_{02}}\right)\left(\frac{\sigma_{c}}{\sigma_{02}}\right)^{m_{2}-1} \exp \left[-V_{e 0}\left(\frac{\sigma_{c} L}{\sigma_{01} x}\right)^{m_{1}}-A_{e 0}\left(\frac{\sigma_{c} L}{\sigma_{02} x}\right)^{m_{2}}\right] \ldots \ldots \ldots \ldots \ldots \ldots \ldots \ldots \ldots \ldots \ldots \ldots \ldots \ldots \ldots \ldots \ldots \ldots \ldots \ldots \ldots \ldots \ldots
\end{aligned}
$$

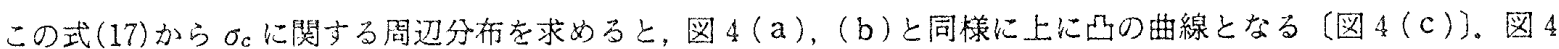

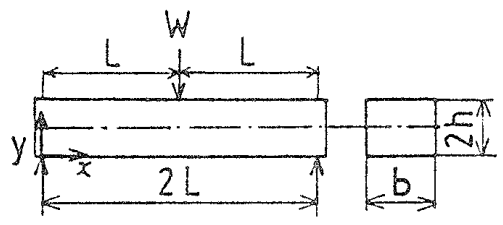

図1三点曲计荷媓を受けるはり
站1 ワイプルパラかータ

\begin{tabular}{c|c|c}
\hline & $\hat{m}_{i}$ & $\hat{\sigma}_{0 i}$ \\
\hline $\begin{array}{c}\text { Inner crack } \\
(i=1)\end{array}$ & 15.79 & 959.9 \\
\hline $\begin{array}{c}\text { Surface crack } \\
(i=2)\end{array}$ & 12.73 & 1295 \\
\hline
\end{tabular}




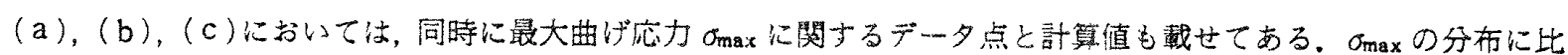

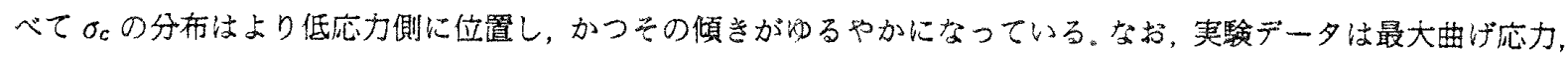

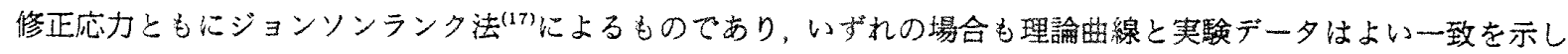
ている。

$4 \cdot 3$ 破壤源深さの分布 次に式(16)の第 1 式，すなわち

$$
h_{0}\left(\sigma_{c}, \xi\right)=2 b m_{1} \sigma_{c}^{m_{1}-1}\left(\frac{1}{\sigma_{01}}\right)^{m_{1}} \exp \left[-V_{e 0}\left\{\frac{\sigma_{c} L h}{\sigma_{01} x(h-y)}\right\}^{m_{1}}\right]
$$

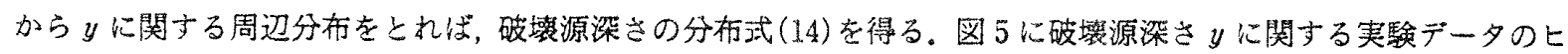
ストグラムと式(14)から計算した理論曲線（実線）を示す。耐者は $y=0$ の近傍を除くと非常によく一致している。

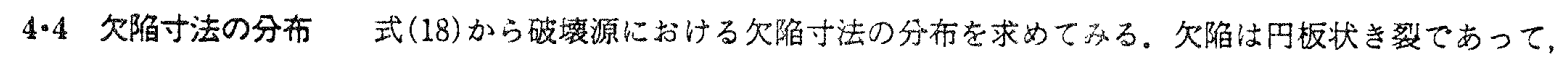

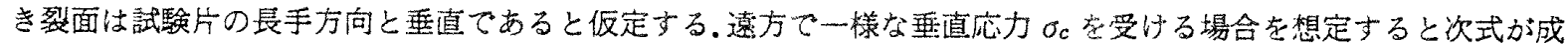
立する。

$$
K_{\mathrm{I} C}=\frac{2}{\pi} \sigma_{c} \sqrt{\pi a}
$$

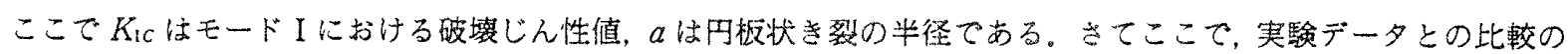
ために式(19)の両辺を $\sqrt{2}$ 倍し，円板状き翌の直径に関する式を求虰る。

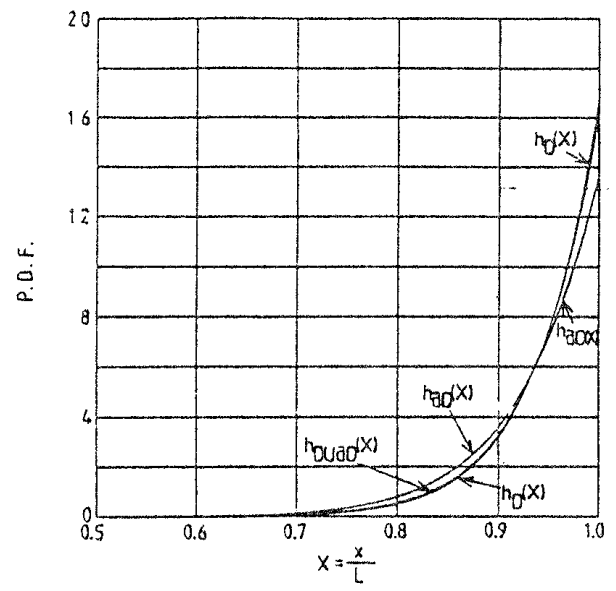

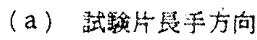

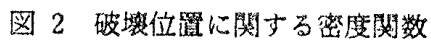

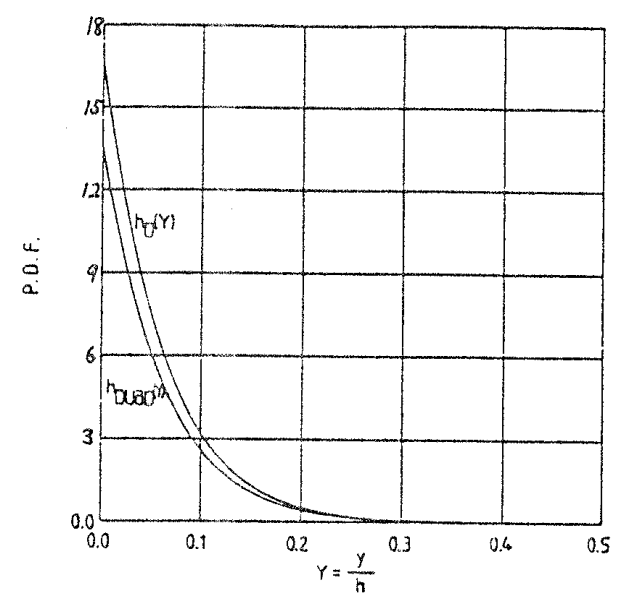

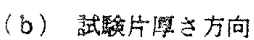

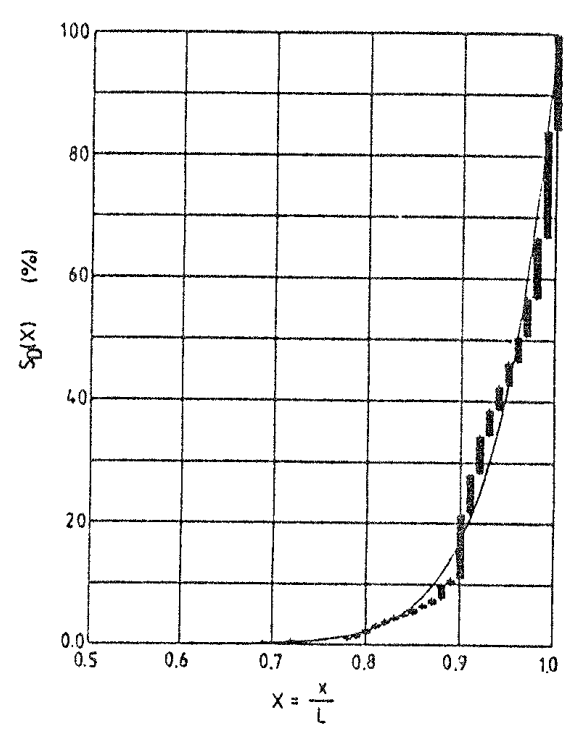

(a)内部破稤

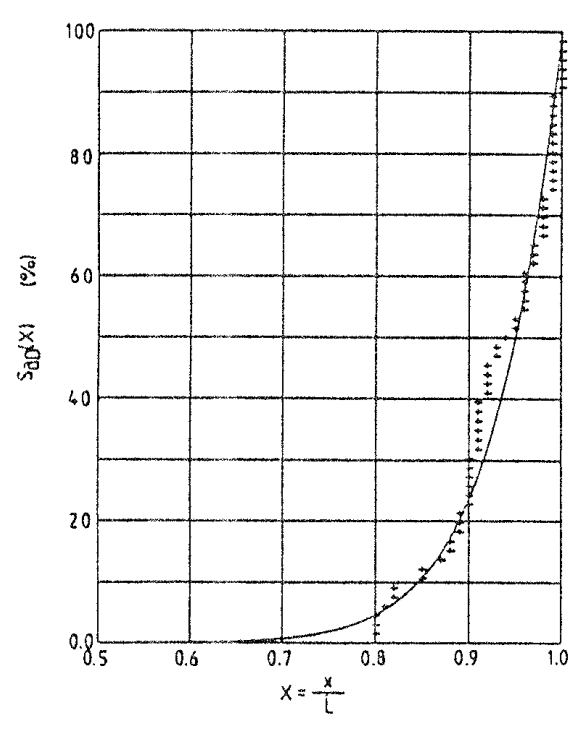

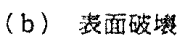

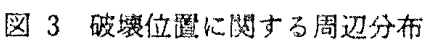




$$
\sqrt{2} K_{\mathrm{I} C}=\frac{2}{\pi} \sigma_{c} \sqrt{\pi d}, d=2 a
$$

式(18)中の $\sigma_{c}$ に関して式(20)の変数変換を行うと次式となる。

$$
h_{D}(d, \xi)=b m_{1}\left(\frac{K_{1} c \sqrt{\pi}}{\sqrt{2} \sigma_{01}}\right)^{m_{1}} \cdot d^{-\left(m_{1}+2\right) / 2} \cdot \exp \left[-V_{00}\left\{\frac{K_{1} \sqrt{\pi}}{\sqrt{2} \sigma_{01}} \frac{L h}{x(h-y) \sqrt{d}}\right\}^{m_{1}}\right] \ldots
$$

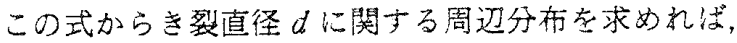

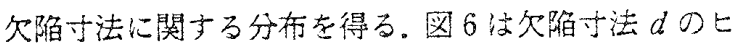
ストグラムであって, $d=35 \mu \mathrm{m}$ 付近に最頻値を持つ。 これに対して，奏線で示した理論曲線你最頻值は一致

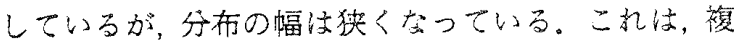

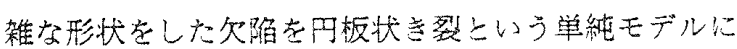
置き橆えたことによるものと思われる。

\section{5. 綰言}

本諭文で纺，多重モードワイブル分布と Finnie ら による位置の確染諭とを結合した理論を新たに定式化 し，その芯用として種々の周辺分布等計算し、これ を用いて伊藤らの行った空化珪素三点曲げ試駼の実跧 データ䰻析した結果，以下のことがわかった。

（1）新たに提唱した理論から陚験片の舆手方向か

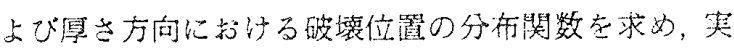
験データと比較した結果, 車者はよく一致した。

(2) 修正応力 $\sigma_{c}$ に関孛万周辺分布を求めたとこ ろ，2贯数ワイブル分布と牥ならずそのワイブルブロ ットは上に凸となった。そのため，修正応力を用いて ワイブル俰数（2 母数）を求好る方法活誤まりである ことが明らかとなった。
（3）欠陒の形状を以板状裂と仮定して, 破壊源 の欠趼寸法の分布の解析を行ったところ, 最頻值に関 して洫添実鈳データと一致した。

終わりに，贵重な实験データの詳細を提供して下ょ

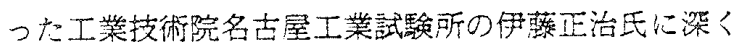
感謝する。

\section{(付録]}

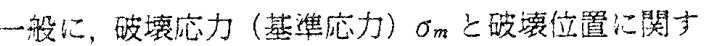

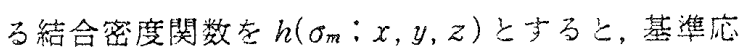
力が $\left(\sigma_{m}, \sigma_{m}+d \sigma_{m}\right)$, 位置が $\{(x, x+d x),(y, y+d y)$,

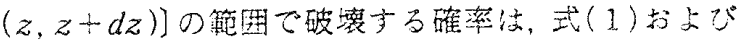
式(2)の第 1 式を用いると，下式のように表艺れる

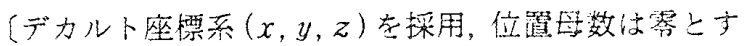
b).

$$
\begin{aligned}
& h\left(\sigma_{m} ; x, y, z\right) d \sigma_{m} d x d y d z \\
& \quad=\exp \left[-\left\{\int_{v} f^{m}(x, y, z) d x d y d z\right\}\left(\frac{\sigma_{m}}{\sigma_{0}}\right)^{m}\right] \\
& \quad \times\left\{\frac{f(x, y, z)}{\sigma_{0}}\right\}^{m} \cdot m \sigma_{m}^{m-1} \cdot d \sigma_{m} d x d y d z
\end{aligned}
$$

たたし， $\sigma=\sigma_{m} \cdot f(x, y, z) て ゙ あ り, f(x, y, z)$ 梳考 えている物体の形状と境界条件によって定まる座標の

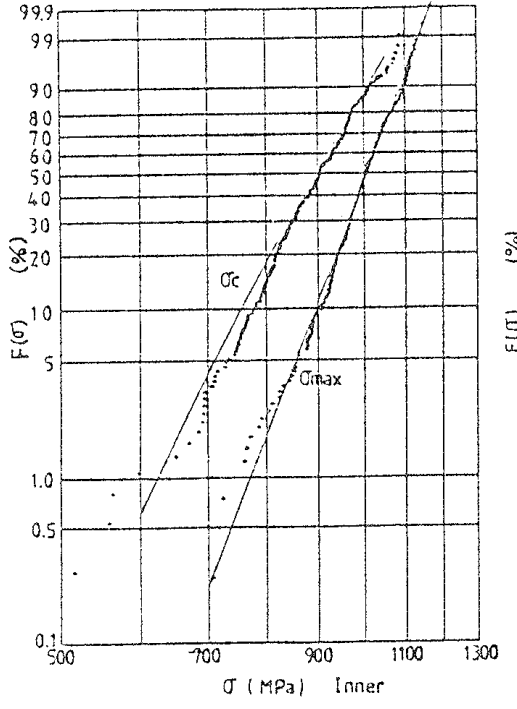

(a)

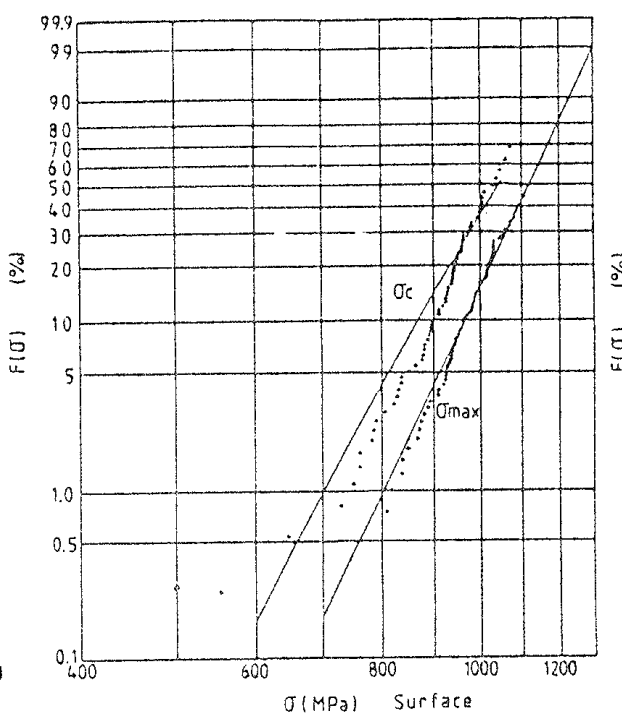

(b)

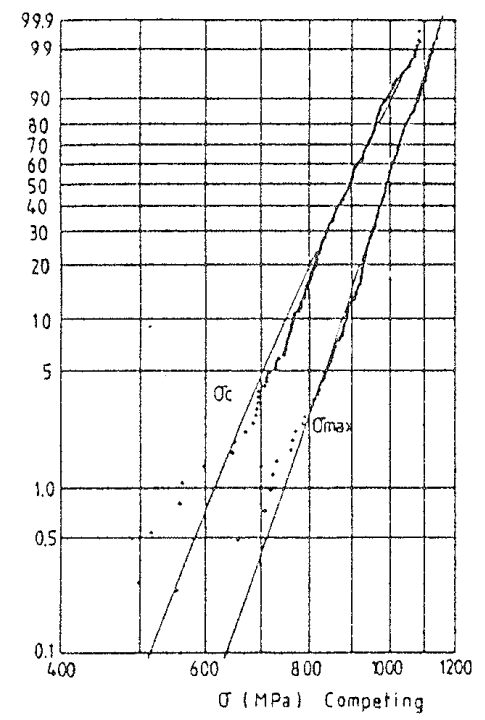

(c)

图4毁大曲げ応力と修证空力のワイブルプロット $\left(+\cdots \cdots \sigma_{\max }, \Delta \cdots \cdots \sigma_{c}\right)$

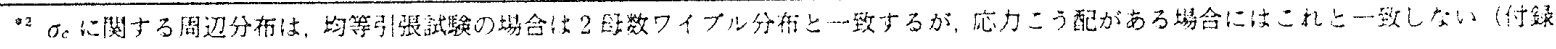
1 参照)
} 


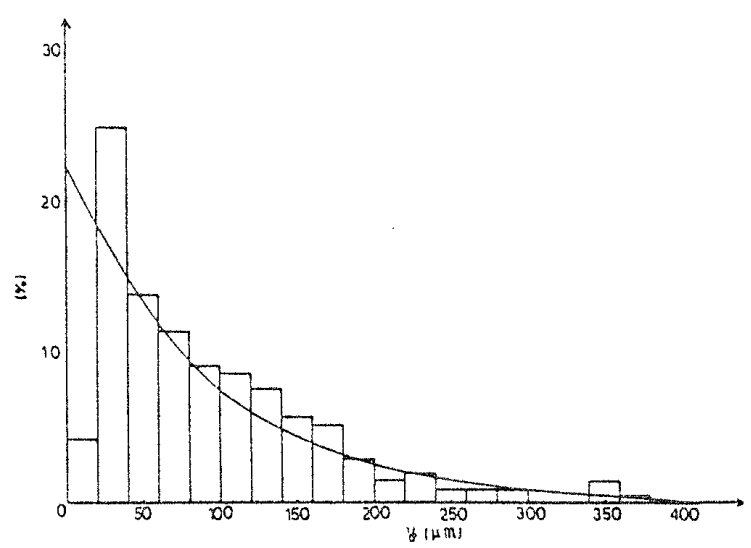

図 5 破壊源媣さの分有

みの関数である。

式 (22)中の $\sigma_{m}$ を修正応力 $\sigma_{c}$ へ変換すると, 次の上 うになる。

$$
\begin{aligned}
\sigma_{m} & =\frac{\sigma_{c}}{f(x, y, z)},|J|=\left|\frac{\partial \sigma_{m}}{\partial \sigma_{c}}\right|=\frac{1}{f(x, y, z)} \\
\therefore \quad & h\left(\sigma_{c} ; x, y, z\right) d \sigma_{c} d x d y d z \\
& =m \sigma_{c}^{m-1}\left(\frac{1}{\sigma_{0}}\right)^{m} \cdot \exp \left[-\left\{\int_{V} f^{m}(x, y, z) d x d y d z\right\}\right. \\
& \left.\times\left\{\frac{\sigma_{c}}{\sigma_{0} \cdot f(x, y, z)}\right\}^{m}\right] d \sigma_{c} d x d y d z \cdots \cdots \cdots(23)
\end{aligned}
$$

上式で，物体の全領域 $V$ に関する䅡分項を便宜上 $V_{e}$ と琶くと。

$h\left(\sigma_{c} ; x, y, z\right) d \sigma_{c} d x d y d z$

$$
\begin{aligned}
& =m \sigma_{c}^{m-1} \cdot\left(\frac{1}{\sigma_{0}}\right)^{m} \cdot \exp \left[-V_{e}\left(\frac{\sigma_{c}}{\sigma_{0}}\right)^{m}\right. \\
& \left.\times f^{-m}(x, y, z)\right] d \sigma_{c} d x d y d z
\end{aligned}
$$

よって，的に関する周辺分布 $F\left(\sigma_{c}\right)$ は

$$
\begin{gathered}
F\left(\sigma_{c}\right)=\int_{0}^{\sigma_{c}} \int_{V} h\left(\sigma_{c} ; x, y, z\right) d \sigma_{c} d x d y d z \\
=\int_{0}^{\sigma_{c}} m \cdot \sigma_{c}^{m-1} \cdot\left(\frac{1}{\sigma_{0}}\right)^{m} \int_{V} \exp \left[-V_{e}\left(\frac{\sigma_{c}}{\sigma_{0}}\right)^{m}\right. \\
\left.\quad \times f^{-m}(x, y, z)\right] d x d y d z d \sigma_{c} \quad \cdots \ldots \ldots \ldots \ldots(
\end{gathered}
$$

となる。

式(24)は，次に示す等式が成立する埸合にのみ，2 母数ワイブル分布となる。

$$
\begin{array}{r}
\int_{V} \exp \left[-V_{e}\left(\frac{\sigma_{c}}{\sigma_{0}}\right)^{m} \cdot f^{-m}(x, y, z)\right] d x d y d z \\
=V_{e} \cdot \exp \left[-V_{e}\left(\frac{\sigma_{c}}{\sigma_{0}}\right)^{m}\right] \ldots \ldots \ldots \ldots \ldots \ldots \ldots
\end{array}
$$

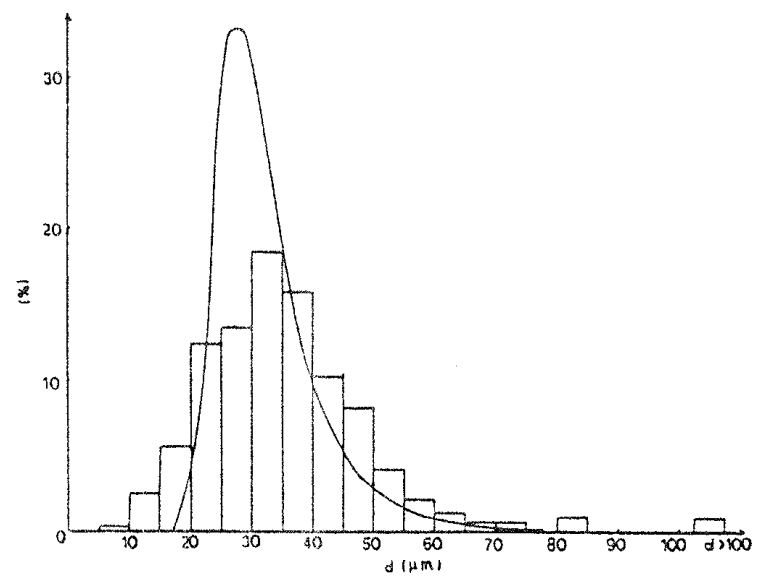

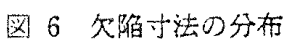

上式流，均等引張 $\left[f(x, y, z)=1, V_{e}=V\right]$ 以外の応 力状態に対して注一般に成立しない。したがって，応 力こう配がある場合。F( $F\left(\sigma_{c}\right)$ 的 2 母数ワプル分布と はならない。このことは式(2)中の第 2 ，第 3 式に対 しても同様に成立する。

\section{文献}

(1) Bolotin, V.V., Statistical Methods in Structural Mechanics, Holden-Day, (1969).

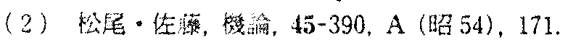

（3）松尾，㙨敛，46-406，A（昭 55)，605.

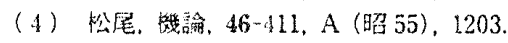

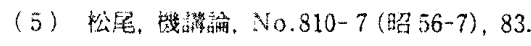

(6) Johnson, C.A., in Fracture Mechanics of Ceramics (Bradt 活加糄) 5 (1983), 365, Plenum Press.

(7) Batcorf, S. B., in Fracture Mechanics of Ceramics (Bradt 嫖か䋧), 3 (1978), 1, Plenum Press.

(8) Evans, A. G., J. Amer. Ceram. Soc., 61-302 (1978).

(9) Moeschberger. M. L. and David. H. A., Biometrics, 27 (1971), 909.

（10）筧川，品筫，12 (昭 57)，23.

(11) Finnie, I., Int. f. Fract. Wech, 6 (1970), 287-300.

(12) AOKI. S., OHTA, I., OHNABE, H., and SAKATA, M., Int. J. Fract. Mech. 21 (1983). 285.

（13）策口・活加 2 名，数学公式 I，53.

（14）伊藤・棌2 2 名，村料，30-1019(昭 56).

（15）松轮・活加1名，材料，33-375(昭 59)

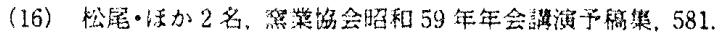

(17) Johnson, L.G., The statistical treatment of fatigue experiment, Elsevier, New York (1964).

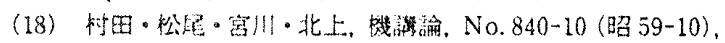
62. 


\section{討論}

(簤問)中川隆夫神戸大学工学部〕

ぜい性材料の破堙に関する多重モードワイブル分布 の適用について不断の努力を重和られて扔り，その成 果を挙げておられることに敏意を表す。以下の点につ き,三質間する。

（1）式(15)，(16)の前後の文望で，2母数ワイブ ル分布に従うか否かを論じているが，図 4(a)，(b) では2夷数ワイブル分布に従わない（直線にならず， なな゙らかだが上に凸の曲線になる）とあるが，图から 屾3母数ワイブル分布なら合う上うに見える。なぜ 母数ワイプル分布の適合性のみを述べているのか。確 率紙上で分布の適合性を論ずるときには，当然，3母 数も考えねばならない（２２身数で適合しなくても3 母数で適合するこ上も市る)。

（2）質問(1)と関係して，付録の6 行如，位笽母
数をなぜ零にしたのか。

【回答〕（1）該当の文意以， $\sigma_{\max }$ が 2 母数ワイ ブル分布に徒ったとしても的法それに徒わず，その ワイブルブロットが非線形になること条述へたもので 南る。

な㧧，図 4(a)，(b)に示した $\sigma_{\max }$ の分布について 3 母数ワイブル分布を当てはめたところ，位置母数が ほ果零に近い値 $\left(\sigma_{u 1}=0.707, \sigma_{u 2}=0.553\right)$ となったの で，实用的に流 2 母数ワイプル分布で十分と考えて， 表1に示したパラメータの推定值を計算に用いた。

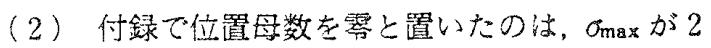
母数ワイブル分布に従ったとしても，变数変換によっ

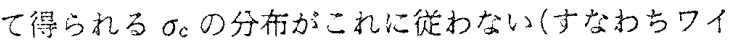
プル・プロットが非線形となる)ことを証明するため である。 